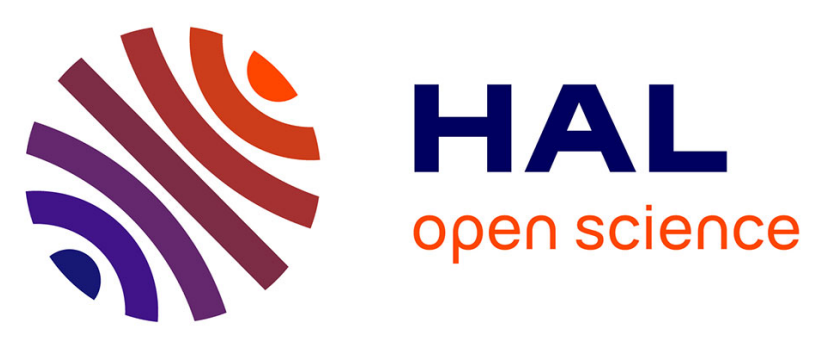

\title{
Effects of demethylfruticuline A and fruticuline A from Salvia corrugata Vahl. on biofilm production in vitro by multiresistant strains of Staphylococcus aureus; Staphylococcus epidermidis and Enterococcus faecalis
} A.M. Schito, G. Piatti, M. Stauder, A. Bisio, E. Giacomelli, G. Romussi, C. Pruzzo

\section{To cite this version:}

A.M. Schito, G. Piatti, M. Stauder, A. Bisio, E. Giacomelli, et al.. Effects of demethylfruticuline A and fruticuline A from Salvia corrugata Vahl. on biofilm production in vitro by multiresistant strains of Staphylococcus aureus; Staphylococcus epidermidis and Enterococcus faecalis. International Journal of Antimicrobial Agents, 2011, 37 (2), pp.129. 10.1016/j.ijantimicag.2010.10.016 . hal-00659898

\section{HAL Id: hal-00659898 https://hal.science/hal-00659898}

Submitted on 14 Jan 2012

HAL is a multi-disciplinary open access archive for the deposit and dissemination of scientific research documents, whether they are published or not. The documents may come from teaching and research institutions in France or abroad, or from public or private research centers.
L'archive ouverte pluridisciplinaire HAL, est destinée au dépôt et à la diffusion de documents scientifiques de niveau recherche, publiés ou non, émanant des établissements d'enseignement et de recherche français ou étrangers, des laboratoires publics ou privés. 


\section{Accepted Manuscript}

Title: Effects of demethylfruticuline A and fruticuline A from Salvia corrugata Vahl. on biofilm production in vitro by multiresistant strains of Staphylococcus aureus;

Staphylococcus epidermidis and Enterococcus faecalis

Authors: A.M. Schito, G. Piatti, M. Stauder, A. Bisio, E.

Giacomelli, G. Romussi, C. Pruzzo

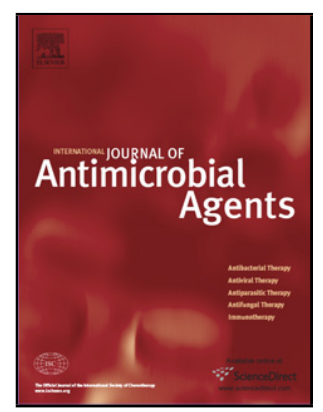

PII:

DOI:

S0924-8579(10)00477-2

Reference: doi:10.1016/j.ijantimicag.2010.10.016

ANTAGE 3470

To appear in: International Journal of Antimicrobial Agents

Received date: $\quad 16-8-2010$

Revised date: $\quad 6-10-2010$

Accepted date: $\quad 8-10-2010$

Please cite this article as: Schito AM, Piatti G, Stauder M, Bisio A, Giacomelli E, Romussi G, Pruzzo C, Effects of demethylfruticuline A and fruticuline A from Salvia corrugata Vahl. on biofilm production in vitro by multiresistant strains of Staphylococcus aureus; Staphylococcus epidermidis and Enterococcus faecalis, International Journal of Antimicrobial Agents (2010), doi:10.1016/j.ijantimicag.2010.10.016

This is a PDF file of an unedited manuscript that has been accepted for publication. As a service to our customers we are providing this early version of the manuscript. The manuscript will undergo copyediting, typesetting, and review of the resulting proof before it is published in its final form. Please note that during the production process errors may be discovered which could affect the content, and all legal disclaimers that apply to the journal pertain. 


\section{Effects of demethylfruticuline A and fruticuline A from Salvia} corrugata Vahl. on biofilm production in vitro by multiresistant strains of Staphylococcus aureus, Staphylococcus epidermidis and Enterococcus faecalis

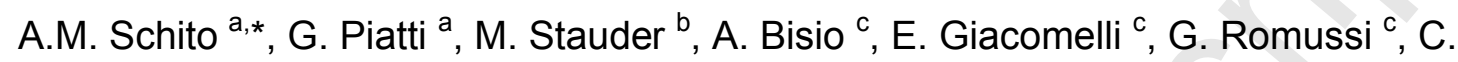
Pruzzo $^{d}$

${ }^{a}$ Department of Surgical Science, University of Genoa, Largo R. Benzi 10, 16132 Genoa, Italy

${ }^{\mathrm{b}}$ Department of Biomedical Science, University of Ancona, Piazza Roma 22, 60121 Ancona, Italy

${ }^{\mathrm{c}}$ Department of Chemical and Technological Science, University of Genoa, Via Brigata Salerno, 16147 Genoa, Italy

${ }^{d}$ Department of Biology, University of Genoa, Viale Benedetto XV, 516132 Genoa, Italy

\section{ARTICLE INFO}

Article history:

Received 16 August 2010

Accepted 8 October 2010

Keywords:

Biofilm 
Quinones

Multiresistant

Staphylococcus aureus

Staphylococcus epidermidis

Enterococcus faecalis

* Corresponding author. Tel.: +39 010353 7753; fax: +39 0103537651.

E-mail address: amschito@unige.it (A.M. Schito). 


\section{ABSTRACT}

In this study, demethylfruticuline $A(\mathrm{df} A)$ and fruticuline $A(f A)$, two quinones representing the mayor diterpenoid components of the exudate produced by the aerial parts of Salvia corrugata, were assessed for their ability to modify surface characteristics, such as hydrophobicity, and to inhibit synthesis of biofilm in vitro by multiresistant Staphylococcus aureus, Staphylococcus epidermidis and Enterococcus faecalis. Five strains of $S$. aureus (three meticillin-resistant and two meticillinsusceptible), five strains of $S$. epidermidis (four meticillin-resistant and one meticillinsusceptible) and eight vancomycin-resistant $E$. faecalis, all recently isolated from clinical specimens and capable of slime production, were studied. fA decrease by at least two-fold the hydrophobic properties of the $S$. aureus cell membrane but did not affect $S$. epidermidis or $E$. faecalis. Biofilm formation on polystyrene plates was quantified spectrophotometrically by established methodologies. Inhibition of biofilm formation was also confirmed by the Congo red agar plate assay. dfA and fA were more effective against $S$. aureus strains (>70\% effect at subinhibitory concentrations) than against $S$. epidermidis in inhibiting slime synthesis. Against $E$. faecalis, dfA at subinhibitory concentration induced an inhibition of biofilm production of ca. $60 \%$; fA was less active and more strain-dependent. Moreover, the two compounds were shown to posses chelating activity on divalent and trivalent metal cations. Interactions of $\mathrm{fA}$ and $\mathrm{dfA}$ with bacteria could be very complex, possibly being species-specific, and could depend not only on inhibition of exopolysaccharide synthesis but also on their chelating activity and on changes in the microorganism's surface, including cell hydrophobicity. 


\section{Introduction}

Bacterial biofilms are complex and highly structured communities of sessile microorganisms embedded in a self-produced extracellular matrix of exopolysaccharide (EPS) and irreversibly attached on various surfaces $[1,2]$. The presence of these microbial communities is often associated with various chronic diseases (including cystic fibrosis, periodontitis, chronic prostatitis, otitis media, endocarditis and recurrent urinary tract infections) [3] and is also responsible for the alarming spread of slime-associated nosocomial infections, mainly due to the increasing use of implanted medical devices of polymeric origin [4]. Biofilmassociated bacteria often tolerate conditions that would eliminate their planktonic counterparts and also show great tolerance toward antibiotics and host immune defences $[5,6]$. Eradication of these communities is rarely achieved, with dire consequences for patients. Gram-positive bacteria, particularly Gram-positive cocci such as Staphylococcus aureus, Staphylococcus epidermidis and Enterococcus faecalis, are extremely important pathogens in the hospital environment and are able to colonise a great variety of medical devices of polymeric origin [7-9].

In the European setting, the findings of the European surveillance of ICU-acquired infections (HELICS-ICU) indicated that coagulase-negative staphylococci (CoNS) were isolated in $17.5-40.7 \%$ of Intensive Care Unit-acquired bloodstream infections and that $S$. aureus were isolated in $7.1-19 \%$ [10]. In addition, the prevalence of $S$. aureus isolates resistant to meticillin and, by definition, to all $\beta$-lactam drugs [meticillin-resistant S. aureus (MRSA)] was shown to range from $32.4 \%$ to $53.3 \%$ of the cases [10]. With regard to CoNS, the incidence of meticillin resistance is even 
more widespread. In fact, despite marked geographic variations, in some areas of Europe $>60 \%$ of CoNS are meticillin-resistant and multiresistant $[11,12]$.

Enterococcus faecalis was also investigated in this study since it is the most common enterococcal species responsible for $80-90 \%$ of human enterococcal infections [13]. The prevalence of biofilm production observed in this pathogen is higher than that reported for Enterococcus faecium and biofilm formation is considered to represent an important factor in the pathogenesis of enterococcal infection [9]. The occurrence of vancomycin-resistant enterococci, their most alarming trait, has progressively increased in the USA and in some parts of Europe over the past 5 years and it is very difficult to control [14].

This situation can be expected to further complicate treatment and potentially lead to increased morbidity and mortality. The need for new classes of antibacterial compounds with activity against multiresistant pathogens has therefore become urgent. Several reports are available describing the action of naturally occurring molecules as antimicrobial agents [15-17]. Such plant preparations are often used as antibacterial agents in traditional medicine $[18,19]$. Terpenoids, glycosteroids, flavonoids and polyphenols are small molecules (molecular weight $<500 \mathrm{Da}$ ) naturally produced by plants that can inhibit many bacterial species, particularly Gram-positive organisms. These compounds are receiving sustained attention regarding their potential use since there has been strong evidence that they possess, in addition to antimicrobial activity, anti-inflammatory and antitumour properties $[20,21]$. 
The genus Salvia includes more than 900 species and is now being intensively studied in view of the antioxidant, antibacterial and antifungal properties that many exudation products, mainly containing ursolic and oleanolic acids, have been shown to posses [22-25].

We recently focused our studies on an exudation product obtained from the fresh aerial part of Salvia corrugata Vahl., an American species of subgenus Calosphace, section Corrugatae, that contained several active compounds, some of which (such as ursolic and oleanolic acid) are already well characterised in their antimicrobial activity $[23,26,27]$. We have described the strong antibacterial activity of two highly oxidised diterpene quinones, fruticuline $A(f A)$ and demethylfruticuline $A(d f A)$, in $S$. corrugata exudate against several multiresistant Gram-positive human pathogens [28]. Moreover, the biological effects dfA on mammalian cells lines were also recently investigated [29].

The aim of the present study was to investigate further the antibacterial properties of $\operatorname{df} A$ and fA by assessing whether the two molecules are able to interfere with the ability of multidrug-resistant (MDR) clinical isolates of S. aureus, S. epidermidis and E. faecalis to produce biofilms. 


\section{Materials and methods}

\subsection{Microorganisms}

Five strains of $S$. aureus (three MRSA and two meticillin-susceptible), five strains of S. epidermidis (four meticillin-resistant and one meticillin-susceptible) and eight strains of vancomycin-resistant $E$. faecalis, all recently isolated from clinical specimens and identified according to standard procedures [30], shown to be capable of slime production were studied.

\subsection{Compounds}

dfA and fA were extracted and isolated from leaf surface constituents as previously described [28]. Briefly, fresh aerial parts of S. corrugata Vahl. were immersed in $\mathrm{CH}_{2} \mathrm{Cl}_{2}$ for $20 \mathrm{~s}$. After filtration and removal of the extraction solvent, the exudate (25 $\mathrm{g}, 0.96 \% \mathrm{w} / \mathrm{w}$ of fresh plant) was chromatographed in portions of $1.0 \mathrm{~g}$ on a Sephadex ${ }^{\mathrm{TM}} \mathrm{LH}-20$ column using $\mathrm{CHCl}_{3} / \mathrm{MeOH}$ (7:3) as an eluent. The eluate fractions were combined by thin layer chromatography to obtain four main fraction groups (I-IV): group I, which was rich in waxy inactive compounds; group II, which was shown to be a crystalline mixture of ursolic acid and oleanolic acid; group III, which was extracted with hot hexane and gave a residue that crystallised from $\mathrm{EtOH}$, yielded crude $\mathrm{fA}$ (purified by recrystallisation from $\mathrm{CHCl}_{3} / \mathrm{EtOH}$ ); and group IV, which was crystallised from EtOH and yielded crude dfA. The amounts of the compounds obtained were $4.2 \mathrm{~g}$ for the mixture of ursolic and oleanolic acids, $0.76 \mathrm{~g}$ for $\mathrm{fA}$ and $2.8 \mathrm{~g}$ for dfA. 
Sterile stock solutions of dfA and fA in dimethyl sulphoxide (DMSO) were prepared and, following dilution in appropriate media, were employed in the studies detailed below.

\subsection{Susceptibility tests}

Minimal inhibitory concentrations (MICs) of the two quinones for all the strains studied were determined following the microdilution procedure detailed by the Clinical and Laboratory Standards Institute (CLSI) [31] using cation-adjusted Mueller-Hinton broth (Biolife, Milan, Italy) as the test medium. Briefly, overnight cultures of bacteria were diluted to yield a final concentration of ca. $5 \times 10^{5} \mathrm{cells} / \mathrm{mL}$. Samples were then added to equivalent volumes of various concentrations of dfA and fA distributed on a microplate and prepared from serial two-fold dilutions ranging from $0.015 \mathrm{mg} / \mathrm{L}$ to 256 $\mathrm{mg} / \mathrm{L}$. Following incubation for $24 \mathrm{~h}$ at $37^{\circ} \mathrm{C}$, the lowest concentration of compound that prevented visible growth was recorded as the MIC. All MICs were determined in duplicate.

\subsection{Hydrophobicity test}

Bacterial surface hydrophobicity was evaluated according to Rosenberg [32]. Three selected representative strains (one each of S. aureus, S. epidermidis and $E$. faecalis) were grown overnight in appropriate media. Following incubation, cells were harvested by centrifugation (3500 rpm, $20 \mathrm{~min}$ ), suspended in phosphate buffer (PB) and exposed to $0.5 \times \mathrm{MIC}$ of $\mathrm{dfA}$ or $\mathrm{fA}$ for $1 \mathrm{~h}$ at $37^{\circ} \mathrm{C}$; control suspensions were left untreated. Treated and control suspensions were then washed twice by 
centrifugation at 3500 rpm for 20 min and the bacteria were re-suspended in phosphate-urea-magnesium sulphate (PUM) buffer [32]. Aliquots (1.5 mL) of the bacterial suspensions were added to $1 \mathrm{~mL}$ of $n$-octane. After allowing mixing for 120 s and settling for $10 \mathrm{~min}$ for the separation step, absorbance of the aqueous phase was measured at $400 \mathrm{~nm}$. Hydrophobicity changes in bacterial cells were expressed as percentage of absorbance variation of the PB phase of dfA- or fA-treated versus control suspensions.

\subsection{Detection of slime production by the Congo red agar (CRA) plate assay}

Several strains of $S$. aureus and $S$. epidermidis were screened for qualitative slime production by the CRA plate assay as described by Freeman et al. [33]. All chemicals were supplied by Biolife. Congo red stain was prepared as a concentrated aqueous solution, autoclaved separately and added to the media when the agar had cooled to $55^{\circ} \mathrm{C}$. Plates were inoculated and incubated aerobically for $24 \mathrm{~h}$ at $37^{\circ} \mathrm{C}$. Biofilmpositive strains produced black coloured colonies, whilst biofilm-negative strains were coloured pink. The total test time was $24 \mathrm{~h}$. The CRA test was also used with two representative strains of $S$. aureus and two of $S$. epidermidis to evaluate directly the effect of dfA and fA on slime production. In this latter case, dfA or fA corresponding to $0.5 \times$ MIC relative to the selected strains were added together with the Congo red to the media when the agar had cooled to $55^{\circ} \mathrm{C}$. Control plates containing the Congo red stain but without dfA or fA were also prepared. Plates where then inoculated with the selected isolate and were incubated aerobically for $24 \mathrm{~h}$ at $37^{\circ} \mathrm{C}$. 


\subsection{Detection of biofilm production using the microtitre plate method}

Slime production was detected using the microtitre plate method, and the presence and extent of biofilm structures were quantified spectrophotometrically using a method based on that reported by Cramton et al. [34]. To produce biofilms, $25 \mu \mathrm{L}$ of stationary-phase bacterial cultures were added aseptically to the wells of a 96-well polystyrene tissue culture plate (Corning, Milan, Italy) containing $175 \mu \mathrm{L}$ of tryptic soy broth medium with $0.25 \%$ glucose and were incubated at $37^{\circ} \mathrm{C}$ for $24 \mathrm{~h}$. To evaluate the effect of dfA and $f A$ on biofilm synthesis, the same procedure was followed except that each compound was added to the growth medium at selected concentrations. After $24 \mathrm{~h}$ of exposure, media were discarded and each well was washed three times with phosphate-buffer saline to remove non-adherent cells. Plates were air-dried in an inverted position. Adherent microorganisms were stained with crystal violet. Excess stain was rinsed off with running tap water and the plates were air-dried. Adherent bacterial films were quantified spectrophotometrically by determining the optical density at $570 \mathrm{~nm}\left(\mathrm{OD}_{570}\right)$. Strains producing a biofilm with an $\mathrm{OD}_{570} \leq 0.2$ were considered as negative for biofilm production and were excluded from the study. Each isolate was tested in triplicate. The total test time was $48 \mathrm{~h}$. The results were derived from three separate experiments and $\mathrm{OD}_{570}$ values were expressed as mean \pm standard deviation. The $\mathrm{OD}_{570}$ value obtained for each strain without any added compound was used as the control. The percentages of biofilm formed in the presence of different concentrations of dfA and fA were calculated employing the ratio between the values of $\mathrm{OD}_{570}$ with and without the compound, adopting the following formula: $\left[\left(\mathrm{OD}_{570}\right.\right.$ with drug/ $\mathrm{OD}_{570}$ without drug $\left.) \times 100\right]$. 


\subsection{Chelating activity test}

To demonstrate the ability of the two quinones to chelate metal ions, the similarity of the 11-oxogroup and 12-hydroxygroup of these compounds to the 4-oxogroup and 3hydroxygroup of the flavonols, which are able to chelate cations, was used. Assays for cation-chelating activity were thus performed following the methods described by Mabry et al. [35] and Von Steinegger and Hänsel [36]. Moreover, since Mg acetate is used to provide chelates for the quantitative ultraviolet (UV) determination of hydroxyanthracene derivatives of cathartic drugs, which contain 9-oxo- and 1hydroxy-groups [37], UV spectra of the two quinones were recorded following addition of this reagent and bathochromic shifts of the UV absorption peaks were also observed. The stock solutions of $f A$ and dfA were at a concentration of 0.1 $\mathrm{mg} / \mathrm{mL}$.

\subsection{Statistical analysis}

Student's $t$-test was used to evaluate any significant differences between the $O D_{570}$ values obtained without the two compounds (controls) and those observed in the presence of different concentrations of the two quinones.

\section{Results}

\subsection{Minimal inhibitory concentrations}

The results of susceptibility testing of dfA and $f A$ for the strains studied are given in Table 1. dfA and fA displayed a very narrow distribution of MIC values, ranging from $32 \mathrm{mg} / \mathrm{L}$ to $64 \mathrm{mg} / \mathrm{L}$ and from $16 \mathrm{mg} / \mathrm{L}$ to $32 \mathrm{mg} / \mathrm{L}$ when assayed against $S$. aureus 
and S. epidermidis, respectively. MIC values for fA and dfA were more uniform (32 mg/L each) against, respectively, $S$. aureus and $S$. epidermidis. This suggests a relatively more potent action of dfA against $S$. epidermidis and of fA against $S$. aureus. Interestingly, there was no correlation between MIC values and resistance to meticillin in all strains tested. Against $E$. faecalis, the two quinones displayed a very homogeneous potency, with MIC values not exceeding $64 \mathrm{mg} / \mathrm{L}$.

\subsection{Effect of dfA and fA on cell hydrophobicity}

Considering that surface hydrophobicity plays a key role in the adhesion ability of biofilm-producing bacteria, the ability of $\mathrm{f} A$ and $\mathrm{dfA}$ to promote changes in the cell surface properties of the pathogens was assessed by evaluating the affinity of these bacteria following exposure to the two quinones towards $n$-octane. The two compounds were tested at concentrations corresponding to $0.5 \times \mathrm{MIC}$. fA was able to decrease strongly the hydrophobic properties of the $S$. aureus cell membrane, increasing more than two-fold the percentage of bacteria distributed in the aqueous phase following treatment with the compound (Table 2). In contrast, dfA did not display any effect on the cell hydrophobicity of the same pathogen (Table 2). Moreover, no changes in cell hydrophobicity following fA and dfA exposure were observed in S. epidermidis and E. faecalis (data not shown). 


\subsection{Inhibition of slime synthesis determined by the Congo red agar plate assay in}

\section{Staphylococcus spp.}

Since inhibition of biofilm synthesis might be the result of a negative effect of the compounds on bacterial growth or on slime production or both, it was first verified that the activity of the two quinones on the growth of both bacterial species was indeed negligible at the selected sub-MIC values (data not shown).

To investigate further the role of $\mathrm{fA}$ and $\mathrm{dfA}$ in preventing biofilm synthesis in $S$. aureus and S. epidermidis strains, the ability of the two compounds to inhibit EPS production in the two pathogens was evaluated first by a qualitative method, the CRA plate assay. dfA and fA were used at concentrations corresponding to $0.5 \times \mathrm{MIC}$ calculated for the slime-producing strains being testing and were incorporated into CRA plates to verify whether the developing colonies would turn from black to pink coloured. The experiments were conducted on two selected isolates of $S$. aureus and S. epidermidis and, since the results obtained were identical, only the patterns obtained with $S$. aureus are shown (Fig. 1). Both quinones were clearly able to induce production of pink-coloured colonies instead of the classical black colonies. The effect of the two compounds was evident especially where bacterial colonies were more isolated.

\subsection{Inhibition of slime synthesis determined by the microtitre plate method}

To assess in a quantitative manner the antibiofilm activity of the two compounds, further experiments were conducted using the microtitre plate method. The two quinones dfA and fA displayed clear activity in preventing staphylococcal and 
enterococcal biofilm synthesis. Staphylococcus aureus strains were more susceptible to the inhibitory effect of both compounds compared with S. epidermidis (see Figs 2 and 3). In contrast, S. epidermidis did not display the same sensitivity to fA and dfA when tested at the same sub-MIC dilutions (Figs 2 and 3 ).

In addition, a more variable inhibitory effect of dfA with respect to fA on S. aureus strains was noted at $0.25 \times$ and $0.5 \times$ MIC concentrations (Fig. 2). This behaviour was strongly strain-dependent, irrespectively of the resistance traits possessed by the organisms, and it was not directly related to the drug concentration used. This finding confirmed that dfA displays a more powerful action against $S$. aureus than fA. A similar variability in the activity of dfA was also observed against $S$. epidermidis stains at $0.5 \times$ MIC values (Fig. 2).

The antibiofilm activity of the two quinones on $E$. faecalis was less prominent and was more strain-dependent than that observed against staphylococci. For dfA, the percentages of inhibition of biofilm synthesis ranged from $10.66 \%$ to $85.19 \%$ at $0.25 x$ MIC and from $20.26 \%$ to $89.49 \%$ at $0.5 \times$ MIC for the eight strains tested. fA was active at these sub-MIC values only on five of the eight strains tested, providing an inhibition ranging from $9.35 \%$ to $64.97 \%$ at $0.25 \times \mathrm{MIC}$ and from $17.31 \%$ to $72.54 \%$ at $0.5 \times$ MIC values. These results indicate that dfA is more potent than $\mathrm{fA}$ in homogenously inhibiting biofilm production in E. faecalis. 


\subsection{Chelating activity test}

To evaluate further the possible mechanism of the inhibitory effect of $f A$ and dfA on biofilm formation in staphylococci, the ability of the two quinones to chelate metal ions known to be required for the synthesis and stabilisation of biofilm structures was investigated [38].

The clear bathochromic shifts observed with both reagents demonstrated that these compounds are able to produce a chelate with $\mathrm{Al}^{3+}$, which is stable not only in a neutral environment but also in the presence of acid. Even Mg chelation was stable at physiological range, but it was unstable following addition of $\mathrm{HCl}$ (results shown below).

fA: UV/Vis $\lambda_{\max }\left(\mathrm{CH}_{3} \mathrm{OH}\right) 210,251,277,321,390$ sh nm; $\left(\mathrm{CH}_{3} \mathrm{OH}+\mathrm{AlCl}_{3}\right) 210,259$, $287,318,424 \mathrm{~nm} ;\left(\mathrm{CH}_{3} \mathrm{OH}+\mathrm{AlCl}_{3}+\mathrm{HCl}\right) 210,259,287,318,424 \mathrm{~nm} ;\left(\mathrm{CH}_{3} \mathrm{OH}+\mathrm{Mg}\right.$ acetate) $226,254,282,331,400 \mathrm{~nm} ;\left(\mathrm{CH}_{3} \mathrm{OH}+\mathrm{Mg}\right.$ acetate $\left.+\mathrm{HCl}\right) 231,254,276$, $319,400 \mathrm{~nm}$.

dfA: UVNis $\lambda_{\max }\left(\mathrm{CH}_{3} \mathrm{OH}\right) 208,254,278,319,399$ sh nm; $\left(\mathrm{CH}_{3} \mathrm{OH}+\mathrm{AlCl}_{3}\right) 207,258$, 288, 317, $426 \mathrm{~nm} ;\left(\mathrm{CH}_{3} \mathrm{OH}+\mathrm{AlCl}_{3}+\mathrm{HCl}\right) 207,255,290,318,420 \mathrm{~nm} ;\left(\mathrm{CH}_{3} \mathrm{OH}+\mathrm{Mg}\right.$ acetate) 229, 254, 279, 329, $401 \mathrm{~nm} ;\left(\mathrm{CH}_{3} \mathrm{OH}+\mathrm{Mg}\right.$ acetate $\left.+\mathrm{HCl}\right) 233,254,283$, $323,399 \mathrm{~nm}$. 


\section{Discussion}

Here we studied the biofilm-inhibiting properties of two highly oxidised diterpene quinones, $f A$ and $d f A$, extracted from the surface exudate obtained from the fresh aerial part of S. corrugata Vahl., an American species of the subgenus Calosphace, that is easily grown in Mediterranean coastal areas.

These readily available compounds were shown to reduce, in different ways and with distinct intrinsic potency, the multistep process of biofilm synthesis of several MDR strains of staphylococci and enterococci.

Against staphylococci, dfA and fA displayed MIC values with a very narrow distribution, ranging from $32 \mathrm{mg} / \mathrm{L}$ to $64 \mathrm{mg} / \mathrm{L}$ and from $16 \mathrm{mg} / \mathrm{L}$ to $32 \mathrm{mg} / \mathrm{L}$, respectively. There was no correlation between MIC values and resistance to meticillin, indicating that the two compounds are acting with a different and still uncharacterised mechanism compared with traditional antibiotic drugs. The same feature is even more true for $E$. faecalis, with a single MIC of $64 \mathrm{mg} / \mathrm{L}$.

The ability of the two diterpene quinones to interfere with the crucial and initial docking phase of biofilm formation, when hydrophobic interactions between the bacterial cell wall and the surface to be colonised play a vital role, was first analysed. $\mathrm{fA}$ at $0.5 \times$ MIC values was able to modify greatly the properties of the $S$. aureus surface, decreasing by at least two-fold its hydrophobic nature compared with the untreated control (Table 2). No changes in cell hydrophobicity were observed for $S$. 
aureus when treated with dfA or when of the two quinones were tested against $S$. epidermidis or E. faecalis.

Using one qualitative (CRA for staphylococci) and one quantitative method (microtitre plate for all pathogens), it was demonstrated that dfA and fA possess an inhibitory activity on several biofilm-producing and MDR Gram-positive strains tested. The effect of the two compounds was evident both against $S$. aureus and $S$. epidermidis when evaluated by the CRA qualitative method. This may suggest that the two quinones could interfere with the synthesis of polysaccharides that form the glycocalyx, disrupting their formation and thus reducing the amount of slime that accumulates $[39,40]$. Moreover, when using the quantitative method it became apparent that the inhibition produced by $f A$ against $S$. aureus is not only slightly more substantial but is also more uniform compared with the activity of dfA on the same pathogen (see Figs 3 and 2, respectively). This behaviour could be due to the significant reduction in the hydrophobic surface properties that fA was shown to induce specifically in $S$. aureus. The reduction both in cell wall hydrophobicity and in EPS production could thus contribute to the overall decrease in biofilm synthesis observed with $f A$ in $S$. aureus.

The differences observed between the action of $\mathrm{fA}$ and dfA against $S$. aureus and $S$. epidermidis are probably due to their diverse chemical structure, depending in particular on the absence of the methyl group in dfA. It should be underlined that within these two diterpene quinones, even a minor change in the structural configuration of the molecule (a demethylation in the case of dfA) can greatly modify the functional activity of the compound on bacteria cell wall hydrophobicity. 
The effects of $\mathrm{fA}$ and dfA in preventing biofilm synthesis in E. faecalis were evaluated only by the quantitative method. Against this species, the two quinones displayed a less prominent ability to inhibit biofilm production compared with that in staphylococci. For $\mathrm{fA}$, a more heterogeneous effect within the isolates tested was also apparent. This latter feature may be attributed to chemical and physical heterogeneity of the specific biofilms utilised by the strains studied. Moreover, it appears that cell wall hydrophobicity is not affected in $E$. faecalis by the two quinones, suggesting that other mechanisms excluding modification of surface hydrophobicity may be the target of action of $f A$ and $d f A$.

An alternative and attractive possibility that could explain the mechanism of the inhibitory effect of the two quinones on biofilm synthesis, particularly for dfA on $S$. aureus and possibly for both quinones on $S$. epidermidis and E. faecalis, could be attributed to the chelating effect possessed by the two compounds. It was possible to evaluate the chelating activity of the two quinones by considering that the chemical structures of $\mathrm{fA}$ and dfA belong to the same chemical class as horminone, an abietane diterpene quinone that can penetrate bacterial cells as a $\mathrm{Mg}^{2+}$ chelate [41]. We have supposed the same activity for the two quinones and utilised the similarity of the 11-oxogroup and 12-hydroxygroup of these compounds to the 4-oxogroup and 3-hydroxygroup of the flavonols, which are able to chelate cations, to demonstrate the ability of fA and dfA to chelate metal ions. As with the flavonoids, chelation with $\mathrm{Al}^{3+}$ is detected by bathochromic shifts of the UV absorption peaks and is used for the systematic identification of these molecules [35]. We thus compared the UV spectra of $f A$ and dfA in methanol with the spectra obtained after addition of $\mathrm{AlCl}_{3}$ and 
$\mathrm{AlCl}_{3} / \mathrm{HCl}$ [35]. The results obtained demonstrated that $\mathrm{f}$ and dfA are able to chelate biologically important bivalent and trivalent cations that are stable in a neutral environment.

These results indicate that interactions of $f A$ and dfA with Gram-positive bacteria could be very complex, possibly being species-specific, and could depend not only on EPS synthesis inhibition but also on their chelating activity and on changes in the microorganism's surface, including cell hydrophobicity.

\section{Funding}

This study was supported by a grant of EU INTERREG ALCOTRA project 'AROMA no. 68'.

\section{Competing interests}

None declared.

\section{Ethical approval}

Not required. 


\section{References}

[1] Donlan RM. Biofilms: microbial life on surfaces. Emerg Infect Dis 2002;8:881-90.

[2] Moons P, Michiels CW, Aertsen A. Bacterial interactions in biofilms. Crit Rev Microbiol 2009;35:157-68.

[3] Parsek MR, Singh PK. Bacterial biofilms: an emerging link to disease pathogenesis. Annu Rev Microbiol 2003;57:677-701.

[4] Otto M. Staphylococcus epidermidis—-the 'accidental' pathogen. Nat Rev Microbiol 2009;7:555-67.

[5] Donlan RM. Biofilms on central venous catheters: is eradication possible? Curr Top Microbiol Immunol 2008;322:133-61.

[6] Høiby N, Bjarnsholt T, Givskov M, Molin S, Ciofu O. Antibiotic resistance of bacterial biofilms. Int J Antimicrob Agents 2010;35:322-32.

[7] Speziale P, Visai L, Rindi S, Pietrocola G, Provenza G, Provenzano M. Prevention and treatment of Staphylococcus biofilms. Curr Med Chem 2008;15:3185-95.

[8] McCann MT, Gilmore BF, Gorman SP. Staphylococcus epidermidis devicerelated infections: pathogenesis and clinical management. J Pharm Pharmacol 2008;60:1551-71.

[9] Mohamed JA, Huang DB. Biofilm formation by enterococci. J Med Microbiol 2007;56:1581-8.

[10] Suetens C, Morales I, Savey A, Palomar M, Hiesmayr M, Lepape A, et al. European surveillance of ICU-acquired infections (HELICS-ICU): methods and main results. J Hosp Infect 2007;65(Suppl 2):171-3. 
[11] Stefani S, Varaldo PE. Epidemiology of methicillin-resistant staphylococci in Europe. Clin Microbiol Infect 2003;9:1179-86.

[12] Stefani S. Evolution in the antibiotic susceptibility and resistance [in Italian]. Infez Med 2009;17(Suppl 3):5-12.

[13] Jones ME, Draghi DC, Thornsberry C, Karlowsky JA, Sahm DF, Wenzel RP. Emerging resistance among bacterial pathogens in the intensive care unit-a European and North American Surveillance study (2000-2002). Ann Clin Microbiol Antimicrob 2004;3:14.

[14] Deshpande LM, Fritsche TR, Moet GJ, Biedenbach DJ, Jones RN. Antimicrobial resistance and molecular epidemiology of vancomycin-resistant enterococci from North America and Europe: a report from the SENTRY antimicrobial surveillance program. Diagn Microbiol Infect Dis 2007;58:163-70.

[15] Mahady GB. Medicinal plants for the prevention and treatment of bacterial infections. Curr Pharm Des 2005;11:2405-27.

[16] Itokawa H, Morris-Natschke SL, Akiyama T, Lee KH. Plant-derived natural product research aimed at new drug discovery. J Nat Med 2008;62:263-80.

[17] Potterat O, Hamburger M. Drug discovery and development with plant-derived compounds. Prog Drug Res 2008;65:45, 47-118.

[18] Guay DR. Cranberry and urinary tract infections. Drugs 2009;69:775-807.

[19] Zaidi SF, Yamada K, Kadowaki M, Usmanghani K, Sugiyama T. Bactericidal activity of medicinal plants, employed for the treatment of gastrointestinal ailments, against Helicobacter pylori. J Ethnopharmacol 2009;121:286-91.

[20] Liu J. Oleanolic acid and ursolic acid: research perspectives. J Ethnopharmacol 2005;100:92-4. 
[21] Yogeeswari P, Sriram D. Betulinic acid and its derivatives: a review on their biological properties. Curr Med Chem 2005;12:657-66.

[22] Kamatou GPP, Van Vuuren SF, Van Heerden FR, Seaman T, Viljoen AM. Antibacterial and antimycobacterial activities of South African Salvia species and isolated compounds from S. chamelaeagnea. S Afr J Bot 2007;73:552-7.

[23] Weckesser SK, Engel K, Simon-Haarhaus B, Wittmer A, Pelz K, Schempp $\mathrm{CM}$. Screening of plant extracts for antimicrobial activity against bacteria and yeasts with dermatological relevance. Phytomedicine 2007;14:508-16.

[24] Kuzmaa L, Rozalskib M, Walenckac E, Rozalskac B, Wysokinska H. Antimicrobial activity of diterpenoids from hairy roots of Salvia sclarea L.: salvipisone as a potential anti-biofilm agent active against antibiotic resistant staphylococci. Phytomedicine 2007;14:31-5.

[25] Gonzalez AG, Abad T, Jimenez IA, Ravelo AG, Luis JG, Aguiar Z, et al. A first study of antibacterial activity of diterpenes isolated from some Salvia species (Lamiaceae). Biochem Syst Ecol 1989;17:293-6.

[26] Fontanay S, Grare M, Mayer J, Finance C, Duval RE. Ursolic, oleanolic and betulinic acids: antibacterial spectra and selectivity indexes. J Ethnopharmacol 2008;120:272-6.

[27] Horiuchi K, Shiota S, Hatano T, Yoshida T, Kuroda T, Tsuchiya T. Antimicrobial activity of oleanolic acid from Salvia officinalis and related compounds on vancomycin-resistant enterococci (VRE). Biol Pharm Bull 2007;30:1147-9.

[28] Bisio A, Romussi G, Russo E, Cafaggi S, Schito AM, Repetto B, et al. Antimicrobial activity of the ornamental species Salvia corrugata, a potential new crop for extractive purposes. J Agric Food Chem 2008;56:10468-72. 
[29] Giannoni P, Narcisi R, De Totero D, Romussi G, Quarto R, Bisio A. The administration of demethyl fruticulin A from Salvia corrugata to mammalian cells lines induces 'anoikis', a special form of apoptosis. Phytomedicine 2010;17:449_ 56.

[30] Murray PR, Baron EJ, Pfaller MA, Tenover FC, Yolken RH. Manual of clinical microbiology. 7th ed. Washington, DC: ASM Press; 1999.

[31] Clinical and Laboratory Standards Institute. Performance standards for antimicrobial susceptibility testing; sixteenth informational supplement. Document M100-S16. Wayne, PA: CLSI; 2006.

[32] Rosenberg M. Bacterial adherence to hydrocarbons: a useful technique for studying cell surface hydrophobicity. FEMS Microbiol Lett 1984;22:289-95.

[33] Freeman DJ, Falkiner FR, Keane CT. New method for detecting slime production by coagulase-negative staphylococci. J Clin Pathol 1989;42:872-4.

[34] Cramton SE, Gerke C, Cotz F. In vitro methods to study biofilm formation. Methods Enzymol 2001;336:239-55.

[35] Mabry TJ, Markham KR, Thomas MB. The systematic identification of flavonoids. Berlin/Heidelberg/New York: Springer-Verlag; 1970. p. 51-5.

[36] Von Steinegger E, Hänsel R. Lehrbuch der Pharmakognosie und Phytopharmazie. Berlin, Germany: Springer-Verlag; 1988. p. 421.

[37] European Pharmacopoeia. 4th ed. Strasbourg; Council of Europe; 2002.

[38] Otto M. Staphylococcal biofilms. Curr Top Microbiol Immunol 2008;322:20728.

[39] Teather RM, Wood PJ. Use of Congo red-polysaccharide interactions in enumeration and characterization of cellulolytic bacteria from the bovine rumen. Appl Environ Microbiol 1982;43:777-80. 
[40] Allison DG, Sutherland IW. The role of exopolysaccharides in adhesion of freshwater bacteria. J Gen Microbiol 1987;133:1319-27.

[41] Nicolas I, Vilchis M, Aragon N, Miranda R, Hojer G, Castro M. Theoretical study of the structure and antimicrobial activity of horminone. Int J Quantum Chem 2003;93:411-21. 
Fig. 1. Bacterial colonies of a selected strain of Staphylococcus aureus (F) grown on Congo red agar plates, showing decreasing levels of slime production in the presence of sub-MICs of demethylfruticuline $A(d f A)$ or fruticuline $A(f A):(A)$ black colonies of untreated $S$. aureus; (B) $S$. aureus at $0.5 \times \mathrm{MIC}(16 \mathrm{mg} / \mathrm{L})$ of dfA; and (C) S. aureus at $0.5 \times \mathrm{MIC}(16 \mathrm{mg} / \mathrm{L})$ of $\mathrm{fA} . \mathrm{MIC}$, minimal inhibitory concentration.

Fig. 2. Activity of demethylfruticuline A (dfA) against five Staphylococcus aureus and five Staphylococcus epidermidis strains (\% inhibition).

Fig. 3. Activity of fruticuline A ( $\mathrm{f} A$ ) against five Staphylococcus aureus and five Staphylococcus epidermidis strains (\% inhibition). 


\section{Table 1}

Minimal inhibitory concentrations (MICs) of demethylfruticuline A (dfA) and fruticuline A (fA) for Staphylococcus aureus, Staphylococcus epidermidis and Enterococcus faecalis

\begin{tabular}{|c|c|c|c|}
\hline \multirow[t]{2}{*}{ Microorganism $(n)$} & \multirow[t]{2}{*}{ Strain } & \multicolumn{2}{|c|}{$\mathrm{MIC}(\mathrm{mg} / \mathrm{L})$} \\
\hline & & dfA & $f A$ \\
\hline \multirow[t]{5}{*}{ S. aureus (5) } & $A^{a}$ & 32 & 32 \\
\hline & $\mathrm{B}^{\mathrm{a}}$ & 64 & 32 \\
\hline & $\mathrm{D}$ & 64 & 32 \\
\hline & $\mathrm{F}$ & 32 & 32 \\
\hline & $G^{a}$ & 32 & 32 \\
\hline \multirow[t]{5}{*}{ S. epidermidis (5) } & $1^{a}$ & 32 & 32 \\
\hline & $2^{a}$ & 32 & 32 \\
\hline & $3^{a}$ & 32 & 16 \\
\hline & 4 & 32 & 32 \\
\hline & $7^{a}$ & 32 & 32 \\
\hline \multirow[t]{8}{*}{ E. faecalis (8) ${ }^{\text {b }}$} & 14 & 64 & 64 \\
\hline & 19 & 64 & 64 \\
\hline & 25 & 64 & 64 \\
\hline & 48 & 64 & 64 \\
\hline & 49 & 64 & 64 \\
\hline & 51 & 64 & 64 \\
\hline & 62 & 64 & 64 \\
\hline & 77 & 64 & 64 \\
\hline
\end{tabular}

${ }^{\mathrm{a}}$ Indicates meticillin resistance.

${ }^{\mathrm{b}}$ All enterococci were vancomycin-resistant and multiresistant. 


\section{Table 2}

Effect of demethylfruticuline $A(\mathrm{dfA})$ and fruticuline $A(f A)$ at $0.5 \times$ the minimal inhibitory concentration on Staphylococcus aureus surface hydrophobicity

\begin{tabular}{lll}
\hline & \% aqueous phase & S.D. \\
\hline Control & 36.4 & 7.9 \\
dfA & 32.2 & 12.0 \\
fA & 89.6 & 11.9 \\
\hline
\end{tabular}

S.D., standard deviation. 
Fig 1 (INTENDED FOR COLOUR REPRODUCTION):

(A)

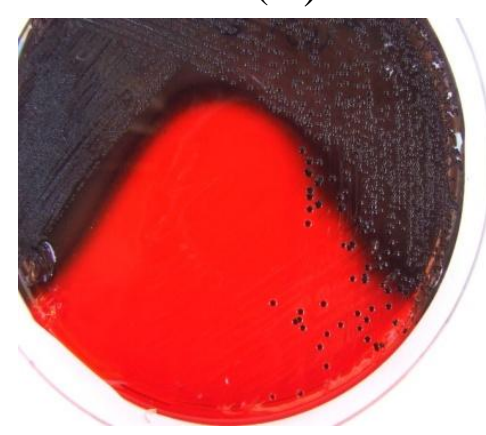

(B)

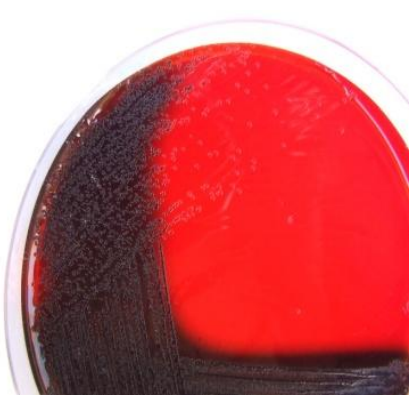

(C)

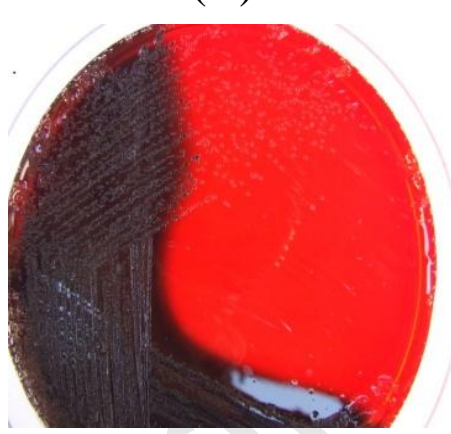




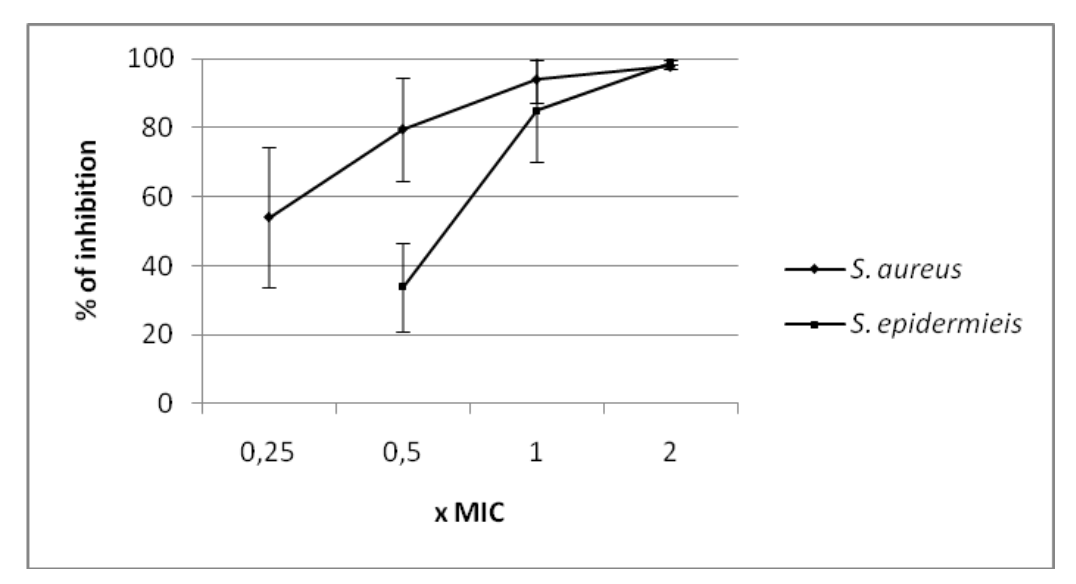




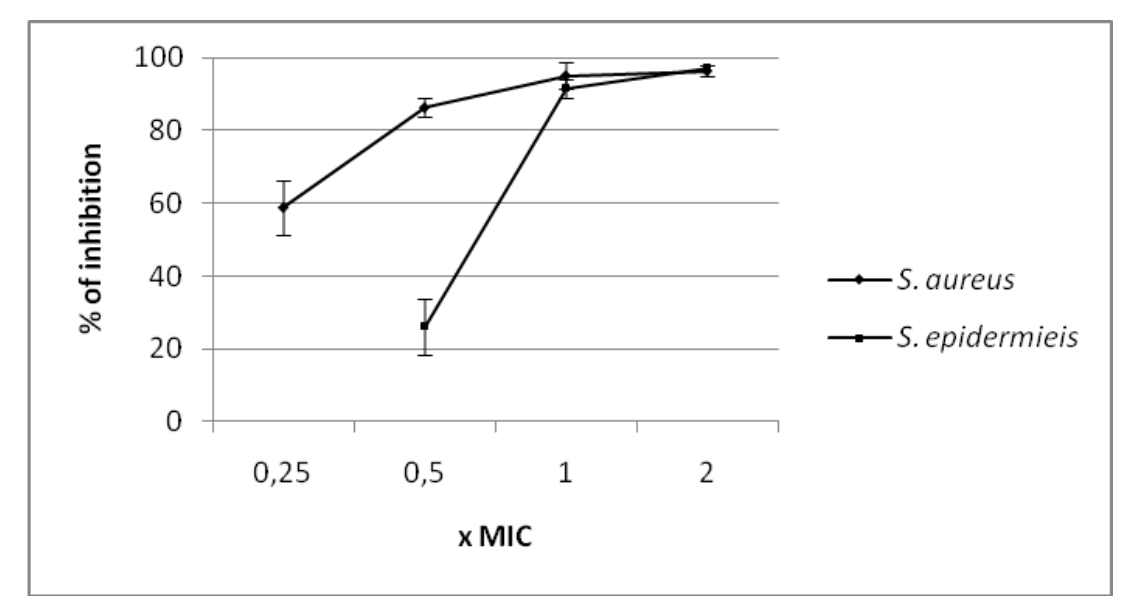

